\title{
A Note on Phrasal Comparatives *
}

\author{
Sigrid Beck \\ Eberhard Karls Universität Tübingen Eberhard Karls Universität Tübingen \\ Sonja Tiemann \\ Eberhard Karls Universität Tübingen
}

\begin{abstract}
This paper investigates the various comparative operators that a language might employ and provides arguments for choosing a particular one. With respect to different phrasal comparatives, we argue that Schoenfinkelization of the operator matters and reflects different crosslinguistic possibilities.
\end{abstract}

Keywords: phrasal comparatives; first language acquisition; crosslinguistic semantic variation; schoenfinkelization

\section{Introduction}

In this paper, we adopt essentially von Stechow's (1984) semantics for the comparative, as recently described in Beck 2011. According to this semantics, an example like (1) has the meaning in (2). The comparative relates two degree maxima and says that the one described by the matrix clause exceeds the one described by the than-constituent. It is not obvious how these truth conditions arise from the surface structure of the example. The von Stechow-style Logical Form (LF) in (3) illustrates that composition in comparatives is notoriously difficult.

(1) My Morning Glory is taller today than it was yesterday.

(2) 'The maximal degree of height that my Morning Glory reaches today exceeds the maximal degree of height that my Morning Glory reached yesterday.'

(3) $\left[\left[-\operatorname{er}\left[\operatorname{than}\left[1\left[\mathrm{it}_{7}\right.\right.\right.\right.\right.$ was $t_{1,\langle d\rangle}$ tall yesterday $\left.\left.\left.]\right]\right]\right]\left[2\left[\mathrm{mMG}_{7}\right.\right.$ is $t_{2,\langle d\rangle}$ tall today $\left.\left.]\right]\right]$

Accordingly, the semantic literature contains numerous suggestions for the derivation of comparative truth conditions (e.g. von Stechow 1984, Heim 1985, Pinkal 1989, Kennedy 1997, and Heim 2001). Recently, the matter has been examined

* We thank Nadine Bade, Rajesh Bhatt, Irene Heim, Stefan Hofstetter, Anna Howell, Chris Kennedy, and Jason Merchant for comments and discussion. Funding for this project was provided by the German Research Foundation (DFG) [Sonderforschungsbereich 833, Projekt C1]. 
Phrasal Comparatives

increasingly from a crosslinguistic perspective (e.g. Beck, Oda \& Sugisaki 2004; Kennedy 2007; Beck, Krasikova, Fleischer, Gergel, Hofstetter, Savelsberg, Vanderelst \& Villalta 2009; and Bhatt \& Takahashi 2011). Strong arguments have been brought forth for the view that the comparative constructions of different languages employ different compositional mechanisms. The semantics of the comparative operator used thus has to be determined on a case-by-case basis. Tiemann, Hohaus \& Beck (2012) provide evidence from language acquisition that even English and German do not possess exactly the same set of comparative operators. Thus, we are faced with the problem of determining, for a given comparative construction, which comparative operator and corresponding path of composition this construction uses. Our paper explores the different empirical predictions that various comparative operators give rise to. Those predictions can guide us in determining the specific comparative operator employed.

Section 2 of this paper collects a set of comparative operators proposed in the literature and relates them to some important properties they predict for comparative constructions. Those predictions can serve as criteria for deciding whether the comparative of a given language employs a particular comparative operator. Section 3 provides evidence from child language acquisition affecting English and German comparatives, and sketches a developmental picture of comparative operators. In section 4 we transfer this picture to language variation. Section 5 concludes the paper.

\section{Comparative Operators}

\subsection{The Issue}

The semantic literature contains numerous suggestions for comparison operators, even when the meaning of the comparative construction as a whole is kept constant. To give a simple example, we assume that the truth conditions of (4) are as in (5).

(4) Mary is taller than John.

(5) $\operatorname{MAX}(\lambda d$.HEIGHT $($ Mary $) \geq d)>\operatorname{MAX}\left(\lambda d^{\prime}\right.$. HEIGHT $($ John $\left.) \geq d^{\prime}\right)$

'The maximal degree of height that Mary reaches

exceeds the maximal degree of height that John reaches.'

Presupposing this much will not allow us to pin down the meaning of the comparative operator -er in (4), however. While some semanticists (for example Heim (1985)) have suggested that the first argument of the comparative operator is an individual, John (type $\langle e\rangle$ ), others (for example von Stechow (1984)) have argued that it is a set of degrees, the height degrees John reaches (type $\langle d, t\rangle$ ). Recent discussion 
(e.g. Bhatt \& Takahashi 2011) strongly indicates that the English example in (4) is to be analyzed along the lines of von Stechow. At the same time, it has become clear that the question of what the semantics of the comparative operator is is likely to receive different answers for the various comparative constructions in different languages. This section collects plausible candidates for comparative operators and illustrates how compositional interpretation proceeds based on their lexical entries (subsection 2.2). It goes on to lay out the properties of comparison constructions that each operator will give rise to (subsection 2.3). The results are summarized in subsection 2.4, providing a guideline for crosslinguistic research in this area. They guide our own empirical investigations in sections 3 and 4.

\subsection{The Operators}

\subsubsection{Comparison to a Degree}

It is possible to combine the comparative operator directly with an expression that denotes a degree. An example is in (6). The lexical entry for the degree comparative in (7) can be traced to Pinkal (1989) and Beck et al. (2004); it allows the compositional interpretation of (6) sketched in (9). ${ }^{1}$

(6) (John is $1.70 \mathrm{~m})$. Mary is taller than that.

$$
\begin{aligned}
& \llbracket-e r_{(\text {degree })} \rrbracket=\lambda \operatorname{Adj}_{\langle d,\langle e, t\rangle\rangle} \cdot \lambda d^{\prime}\langle d\rangle \cdot \lambda x_{\langle e\rangle} \cdot \operatorname{MAX}(\lambda d \cdot \operatorname{Adj}(d)(x))>d^{\prime} \\
& \llbracket \operatorname{MAX} \rrbracket=\lambda D_{\langle d, t\rangle} \cdot \imath d\left[D(d) \& \forall d^{\prime}\left[D\left(d^{\prime}\right) \rightarrow d^{\prime} \leq d\right]\right] \\
& \text { (9) a. Logical Form: [Mary [is [tall -er [than that] ]]] } \\
& \text { b. } \llbracket \text { tall } \rrbracket=\lambda d_{\langle d\rangle} \cdot \lambda x_{\langle e\rangle} \cdot \operatorname{HEIGHT}(x) \geq d \\
& \text { c. } \llbracket \text { tall }-e r_{(\text {degree })} \rrbracket=\lambda d^{\prime} . \lambda x . \operatorname{MAX}(\lambda d \text {. HEIGHT }(x) \geq d)>d^{\prime} \\
& \text { d. } \left.\llbracket \text { tall }-e r_{(\text {degree })} \rrbracket(\llbracket \text { that } \rrbracket)(\llbracket \text { Mary } \rrbracket)=1 \text { iff HEIGHT(Mary }\right)>1.70 \mathrm{~m}
\end{aligned}
$$

It is possible in English that the standard of comparison is not given by a than-constituent. Examples are given in (10a) and (10b). We analyze both examples as contextual comparatives with the Logical Form in (11). The compared to-phrase in (10b) serves to indicate the intended context, but unlike the than-phrase, it is not itself the compositional standard of comparison.

a. (John is $1.70 \mathrm{~m}$.) Mary is taller.

b. Compared to John, Mary is taller.

$$
\text { [Mary [is [tall } \left.\left.\left.-e r_{(\text {degree })} d_{c}\right]\right]\right]
$$

1 It is possible to schoenfinkel this operator differently, as being of type $\langle d,\langle\langle d,\langle e, t\rangle\rangle,\langle e, t\rangle\rangle\rangle$. This re-bracketing may be important in order to make the connection to $-e r_{\text {(clausal) }}$. For the purposes of our discussion, we use the most surface-oriented possibility in (7). 
Phrasal Comparatives

\subsubsection{Clausal Comparatives}

Heim (2001) proposes the comparative operator in (12). This operator has been argued to have a wide range of applications (compare e.g. Beck 2011 and Beck 2012). We illustrate in (14) and (15) how an English clausal comparative such as (13) would be interpreted with the help of the lexical entry provided in (12).

(13) The knife is longer than the drawer is deep.

(14) $\left[\left[-e r_{\text {(clausal) }}\left[\mathrm{MAX}\left[2\right.\right.\right.\right.$ [the drawer $t_{2,\langle d\rangle}$ deep]]]] [1 [the knife $t_{1,\langle d\rangle}$ long]]]

(15) a. $\llbracket\left[2\left[\right.\right.$ the drawer $t_{2,\langle d\rangle}$ deep $\left.]\right] \rrbracket=\lambda d^{\prime}$. DEPTH(the drawer) $\geq d^{\prime}$

b. $\llbracket\left[1\left[\right.\right.$ the knife $t_{1,\langle d\rangle}$ long] $] \rrbracket=\lambda d$. LENGTH(the knife $) \geq d$

c. $\llbracket(13) \rrbracket=1$ iff $\operatorname{MAX}(\lambda d$. LENGTH $($ the knife $) \geq d)>\operatorname{MAX}\left(\lambda d^{\prime}\right.$. DEPTH $($ the drawer $\left.) \geq d^{\prime}\right)$

Note that in (14), there is no meaningful expression longer. The comparative operator and the adjective that carries comparative morphology are interpreted in separate places (a 'discontinuous' analysis in the terms of Pinkal (1989)). Moreover, if we want to apply the comparative operator in (12) to an example like (16) from the beginning of this section, we end up with a fairly abstract analysis-sketched in (17) — with ellipsis, understanding the than-constituent as a reduced clause.

(16) Mary is taller than John.
a. [ [-er(clausal) [MAX [1 [John $t_{1,\langle d\rangle}$ tall]] ]] [2 [Mary $t_{2,\langle d\rangle}$ tall]] ]
b. $\llbracket\left[1\left[\right.\right.$ John $t_{1,\langle d\rangle}$ tall $] \rrbracket=\lambda d^{\prime}$. $\operatorname{HEIGHT}($ John $) \geq d^{\prime}$
c. $\llbracket\left[2\left[\right.\right.$ Mary $t_{2,\langle d\rangle}$ tall $\left.]\right] \rrbracket=\lambda d$. HEIGHT(Mary) $\geq d$
d. $\llbracket(4) \rrbracket=1$ iff $\operatorname{MAX}(\lambda d$. HEIGHT(Mary $) \geq d)>\operatorname{MAX}\left(\lambda d^{\prime} . \operatorname{HEIGHT}(\right.$ John $\left.) \geq d^{\prime}\right)$

\subsubsection{Phrasal Comparatives of Type $\langle\langle d,\langle e, t\rangle\rangle,\langle e,\langle e, t\rangle\rangle\rangle$}

People have looked for a more surface-oriented analysis. The phrasal comparative operator in (18) comes from Kennedy (1997). It permits the simpler analysis in (19) for the example in (4). Note that the than-constituent is a phrase rather than a clause on this analysis, and it contributes an individual, not a set of degrees or a degree.

$$
\begin{aligned}
& \llbracket-e r_{(\text {Kennedy })} \rrbracket=\lambda \operatorname{Adj}_{\langle d,\langle e, t\rangle\rangle} \cdot \lambda y_{\langle e\rangle} \cdot \lambda x_{\langle e\rangle} \cdot \\
& \operatorname{MAX}(\lambda d \cdot \operatorname{Adj}(d)(x))>\operatorname{MAX}\left(\lambda d^{\prime} \cdot \operatorname{Adj}\left(d^{\prime}\right)(y)\right) \\
& \text { a. [Mary [tall -er(Kennedy) }[\text { than John]]] }
\end{aligned}
$$


Beck, Hohaus, Tiemann

b. $\llbracket$ tall $-e r_{(\text {Kennedy })} \rrbracket=$ $\lambda y \cdot \lambda x \cdot \operatorname{MAX}(\lambda d \cdot \operatorname{HEIGHT}(x) \geq d)>\operatorname{MAX}\left(\lambda d^{\prime} . \operatorname{HEIGHT}(y) \geq d^{\prime}\right)$

c. $\llbracket$ tall - er $r_{(\text {Kennedy })} \rrbracket(\llbracket J o h n \rrbracket)(\llbracket$ Mary $\rrbracket)=1$ iff $\operatorname{MAX}(\lambda d$. HEIGHT(Mary $) \geq d)>\operatorname{MAX}\left(\lambda d^{\prime} . \operatorname{HEIGHT}(\right.$ John $\left.) \geq d^{\prime}\right)$

\subsubsection{Phrasal Comparatives of Type $\langle e,\langle\langle d,\langle e, t\rangle\rangle,\langle e, t\rangle\rangle\rangle$}

Kennedy's (1997) analysis is not the first phrasal semantic analysis of the comparative. Heim (1985) favors the phrasal operator given in (20), for reasons that will become clear in a moment. Notice that the difference between (18) and (20) is in how the operator is schoenfinkeled. (20) requires a different Logical Form than (18): As shown in (21a), the comparative operator forms an LF constituent with the than-phrase. The structure results from movement and is more abstract than (19) in that there is no meaningful unit taller.

$\llbracket-e r_{(\text {Heim })} \rrbracket=\lambda y_{\langle e\rangle} \cdot \lambda \operatorname{Adj}_{\langle d,\langle e, t\rangle\rangle} \cdot \lambda x_{\langle e\rangle} \cdot$

$\operatorname{MAX}(\lambda d \cdot \operatorname{Adj}(d)(x))>\operatorname{MAX}\left(\lambda d^{\prime} \cdot \operatorname{Adj}\left(d^{\prime}\right)(y)\right)$

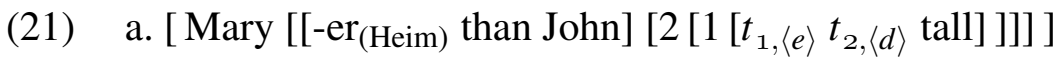

b. $\llbracket\left[-e r_{(\text {Heim })}\right.$ than John $] \rrbracket=$ $\lambda \operatorname{Adj} \cdot \lambda x \cdot \operatorname{MAX}(\lambda d \cdot \operatorname{Adj}(d)(x))>\operatorname{MAX}\left(\lambda d^{\prime} \cdot \operatorname{Adj}\left(d^{\prime}\right)(\right.$ John $\left.)\right)$

c. $\llbracket\left[2\left[1\left[t_{1,\langle e\rangle} t_{2,\langle d\rangle}\right.\right.\right.$ tall $\left.\left.]\right]\right] \rrbracket=\lambda d . \lambda x_{\langle e\rangle}$. $\operatorname{HEIGHT}(x) \geq d$

d. $\llbracket\left[-e r_{(\text {Heim })}\right.$ than John $] \rrbracket\left(\llbracket\left[2\left[1\left[t_{1,\langle e\rangle} t_{2,\langle d\rangle}\right.\right.\right.\right.$ tall $\left.\left.\left.]\right]\right] \rrbracket\right)(\llbracket$ Mary $\rrbracket)=1$ iff $\operatorname{MAX}(\lambda d$.HEIGHT(Mary) $\geq d)>\operatorname{MAX}\left(\lambda d^{\prime} . \operatorname{HEIGHT}(\right.$ John $\left.) \geq d^{\prime}\right)$

Our simple example shows that, technically, at least three different compositional routes to the same interpretation are possible. Next, we turn to reasons one might have for favoring one comparative operator over another.

\subsection{Resulting Properties of Comparative Constructions}

\subsubsection{Contextual Degree Comparatives versus the Others}

In English, degree comparatives and contextual degree comparatives seem fairly identifiable. This is not universally the case, however. There is considerable debate in the literature, for example, regarding whether the yori-constituent in Japanese comparatives should be seen as similar to English (22a) or English (22b); cf. Beck et al. 2004; Kennedy 2007; Oda 2008; Hayashishita 2009; and Shimoyama 2012. The first option indicates an analysis in terms of a degree-denoting than-clause which is compositionally integrated into the semantics. The second option indicates a contextual comparative with a covert degree pronoun; the yori-constituent is part of 
Phrasal Comparatives

the context, not part of the composition. (For the relevant examples from Japanese, see the appendix to this paper.)

(22) a. 'Taro bought a more expensive umbrella than Hanako did.'

b. 'Compared to what Hanako bought, Taro bought a more expensive umbrella.'

So what criteria do people offer to argue for one analysis over the other? We explain below four properties that distinguish contextual comparatives from compositional comparatives. We illustrate them with English compared to-versus than-constituents.

Variation in Acceptability (Beck et al. 2004) It might be more or less obvious to derive a plausible value for the covert degree pronoun in a contextual comparison. Accordingly, some examples should be more straightforward than others. (23a) illustrates that this is the case. Compositional comparatives do not suffer from the same variability, as is illustrated in (23b). This criterion applies to clausal than-constituents.

a. Compared to what John bought, Mary bought a more expensive/?/??/*a longer umbrella.

b. Mary bought a more expensive/a longer umbrella than John did.

Variation in Interpretation (Beck et al. 2004) The value for the degree pronoun in a contextual comparison might not be firmly fixed. The contextual comparison should leave leeway for interpretations that are unavailable for the compositional comparative. (24b) versus (24c) illustrate that this is indeed the case.

(24) a. Context: A clothing store has reduced prices for a number of items. Intended interpretation: The dress got less of a reduction than the coat, although the absolute price of the coat is still above the price of the dress.

b. Compared to the dress, the coat is cheaper.

c. \# The coat is cheaper than the dress.

Filled Degree Argument Slots (Oda 2008) Conceivably, providing a context for a value assignment for the degree pronoun could consist of providing a degree. (25a) shows that this is possible for the contextual comparative, and (25b) shows that a parallel structure is impossible in the compositional comparative. This criterion also applies to than-clauses (and not, obviously, to the well-formed Claudia wrote more than five papers.).

(25) a. Compared to the five papers I wrote, Claudia wrote more papers.

b. * Claudia wrote more papers than I did five. 
Island Sensitivity The relationship between a context setter and a contextual comparative should not be subject to syntactic constraints, whereas the LFs that are the input to compositional interpretation are. The contrast between (26a) and (26b) illustrates that contextual comparison is not sensitive to a relative clause island, while the compositional comparative is.

(26) a. Compared to Bill, John wrote a paper [RelCl that was longer].

b. \# John wrote a paper that was longer than Bill.

\subsubsection{Kennedy's (1997) Phrasal Comparative Operator}

Let us next explore the properties of the comparative operator repeated in (27).

$$
\begin{aligned}
& \llbracket-e r_{(\text {Kennedy) }} \rrbracket=\lambda \operatorname{Adj}_{\langle d,\langle e, t\rangle\rangle} \cdot \lambda y_{\langle e\rangle} \cdot \lambda x_{\langle e\rangle} \cdot \\
& \operatorname{MAX}(\lambda d \cdot \operatorname{Adj}(d)(x))>\operatorname{MAX}\left(\lambda d^{\prime} \cdot \operatorname{Adj}\left(d^{\prime}\right)(y)\right)
\end{aligned}
$$

This operator should give rise to comparatives that are strictly compositional (e.g. no variation in interpretation, island sensitivity). What would distinguish it from the other compositional options? It should be noted that this operator has a fairly limited range of application. It turns out that it is only suitable to derive predicative comparatives. The lexical entry in (27) is such that it will never be able to undergo movement. (28) specifies the abstract LF required for -er (Kennedy). Its sister must be a relational adjective-type constituent, $R$ in (28). Next it combines with a type $\langle e\rangle$ than-phrase followed by another type $\langle e\rangle$ expression, $\mathrm{DP}_{x}$. This is not a problem with predicative adjectives, where the surface structure provides the required constituents in the required order. But when we try to create such an LF by movement, we fail, cf. (29). Creating a constituent of type $\langle d,\langle e, t\rangle\rangle$ would require first moving a type $\langle e\rangle$ constituent $\mathrm{DP}_{x}$ out of the category $R$, and then moving -er (Kennedy) to a position between $\mathrm{DP}_{x}$ and its binder index (an instance of parasitic movement, compare Heim (1985) and Beck \& Sauerland (2000)). This is possible, but does not allow the than-phrase to be integrated into the required argument slot of -er(Kennedy), between the relation and $\mathrm{DP}_{x}$. Standard theory of movement does not allow us to give $-e r_{(\text {Kennedy) }}$ the required order of arguments for non-lexical $\langle d,\langle e, t\rangle\rangle$ relations. $^{2}$

$$
\begin{aligned}
& {\left[\ldots \mathrm{DP}_{x}\left[\left[\text { than } \mathrm{DP}_{y}\right]\left[-\operatorname{er}_{\text {(Kennedy) }}\left[R_{\langle d,\langle e, t\rangle} \ldots\right]\right]\right] \ldots\right]} \\
& \text { a. Surface Structure: }\left[\ldots\left[\operatorname{than} \mathrm{DP}_{y}\right] \ldots\left[R \ldots-\operatorname{er}_{(\text {Kennedy })} \ldots \mathrm{DP}_{x} \ldots\right] \ldots\right] \\
& \text { b. Logical Form: } \\
& \left.\left[\ldots\left[\operatorname{than} \mathrm{DP}_{y}\right] \ldots\left[\mathrm{DP}_{x}\left[-\operatorname{er}_{(\text {Kennedy })}\left[R_{\langle d,\langle e, t\rangle\rangle} \ldots t_{\text {-er }} \text { Kennedy }\right) \ldots t_{\mathrm{DP}_{x}} \ldots\right]\right]\right] \ldots\right]
\end{aligned}
$$

2 If we changed the order of arguments to make the than-phrase last, our syntactic structures would no longer get the predicative comparative right. 
Phrasal Comparatives

The semantics in (27) will only ever be usable for a comparative that combines a than-phrase with a predicative adjective. Attributive adjectives and adverbs cannot make use of - $e r_{\text {(Kennedy) }}$ even when they are followed by a phrasal than-constituent. Than-clauses are also not compatible with this comparative operator because they are not of type $\langle e\rangle$. We expect the picture in (30) of such an operator. It is clear that this is not the picture that English gives us, so (30) should be looked at for the moment as hypothetical data for -er(Kennedy).

$$
\begin{aligned}
& \text { a. Mary is tall -er (Kennedy) than John. } \\
& \text { required relation: }\left[\lambda d_{\langle d\rangle} \cdot \lambda x_{\langle e\rangle} \cdot[\operatorname{HEIGHT}(x) \geq d]\right]=\llbracket \text { tall } \rrbracket \\
& \text { b. * Mary wrote a long -er(Kennedy) paper than John. } \\
& \text { required relation: }\left[\lambda d_{\langle d\rangle} \cdot \lambda x_{\langle e\rangle} \cdot x \text { wrote a } d\right. \text {-long paper] (not lexical) }
\end{aligned}
$$

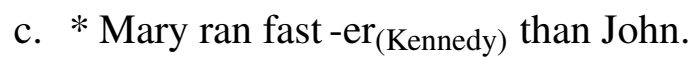

$$
\begin{aligned}
& \text { required relation: }\left[\lambda d_{\langle d\rangle} \cdot \lambda x_{\langle e\rangle} \cdot x \text { ran } d \text {-fast }\right] \text { (not lexical) } \\
& \text { d. * Mary is tall -er(Kennedy) than the bed is long/than I thought. }
\end{aligned}
$$

Furthermore, this phrasal comparative cannot interact scopally with other operators. Consider (31), modeled after Heim 2001. The example is ambiguous, permitting the two readings paraphrased in (32a) and (32b). Heim (2001) shows that the modal takes scope over the comparative in (32a). In (32b), however, the comparative is raised at LF to take scope over the modal. Since a Kennedy-style phrasal comparative operator cannot move, the hypothetical example in (33) - employing the comparative operator less (Kennedy) $_{\text {in }}(34)$ - should be constructable but have only the interpretation in (32a).

(31) John needs to be less tall than Bill.

(32) a. need $\gg-e r$ : 'The following is required: that John be shorter than Bill.'

b. - er $\gg$ need: 'The height minimally required of John is below the height minimally required of Bill.' (minimum requirement reading)

(33) John needs to be less (Kennedy) tall than Bill.

$$
\begin{aligned}
& \llbracket \operatorname{less}_{(\text {Kennedy })} \rrbracket=\lambda \operatorname{Adj}_{\langle d,\langle e, t\rangle\rangle} \cdot \lambda y_{\langle e\rangle} \cdot \lambda x_{\langle e\rangle} \cdot \\
& \operatorname{MAX}(\lambda d \cdot \operatorname{Adj}(d)(x))<\operatorname{MAX}\left(\lambda d^{\prime} \cdot \operatorname{Adj}\left(d^{\prime}\right)(y)\right)
\end{aligned}
$$

\subsubsection{Clausal versus Phrasal Comparatives}

It is obvious that English compositional comparatives need a more powerful comparative operator than -er (Kennedy), since English has attributive, adverbial and clausal comparatives. Our candidates are $-e r_{\text {(clausal) }}$ and $-e r_{(H e i m)}$. What distinguishes comparatives employing (35) versus (36)? 
Beck, Hohaus, Tiemann

$$
\begin{aligned}
& \llbracket-e r_{(\operatorname{Heim})} \rrbracket=\lambda y_{\langle e\rangle} \cdot \lambda \operatorname{Adj}_{\langle d,\langle e, t\rangle\rangle} \cdot \lambda x_{\langle e\rangle} \cdot \\
& \operatorname{MAX}(\lambda d \cdot \operatorname{Adj}(d)(x))>\operatorname{MAX}\left(\lambda d^{\prime} \cdot \operatorname{Adj}\left(d^{\prime}\right)(y)\right) \\
& \llbracket-e r_{\text {(clausal) })} \rrbracket=\lambda d\langle d\rangle \cdot \lambda D_{\langle d, t\rangle} \cdot \operatorname{MAX}(D)>d
\end{aligned}
$$

The obvious difference is the semantic type of the first argument of the comparative operator. A comparison operator that requires a type $\langle e\rangle$ first argument should not be able to combine with a than-clause:

* Mary is tall -er $($ Heim) than the bed is long/than I thought.

Conversely, the clausal comparison operator can only combine with a than-phrase with the help of ellipsis. This will not be obvious from surface appearance:

Mary is tall -er (clausal) than John is tall.

Bhatt \& Takahashi (2011) provide us with a second criterion to distinguish $-e r_{(\mathrm{Heim})}$ from -er (clausal). They observe that the two operators yield different readings in configurations like (39).

(39) More people read every syntax paper than every semantics paper.

a. 'There are more people who read every syntax paper than there are people who read every semantics paper.'

b. [ [-er (clausal) [than [ $\lambda d$. $d$-many people read every semantics paper]]] $[\lambda d$. $d$-many people read every syntax paper] ]

(41) a. 'For every pair $\langle x, y\rangle$ consisting of a syntax paper $x$ and a semantics paper $y$ : More people read $\mathrm{x}$ than $\mathrm{y} . '=$ 'The least read syntax paper was read by more people than any semantics paper.'

b. [every syntax paper $\lambda x$ [every semantics paper $\lambda y\left[x\left[\left[-e r_{(\text {Heim })}\right.\right.\right.$ than $\left.y\right][\lambda d . \lambda z . d$-many people read $\left.\left.\left.\left.z]\right]\right]\right]\right]$

They argue that English allows reading (40) but not (41), and hence English has - $e r_{\text {(clausal) }}$ and does not have $-e r_{(\text {Heim) }}$. By the same argument, Hindi has -er (Heim) and not $-e r_{\text {(clausal) }}$. (Bhatt \& Takahashi (2011) provide further arguments for this conclusion, but we concentrate on their scope argument for our purposes.)

\subsection{Section Summary}

The table in Figure 1 on the next page summarizes the empirical properties that the four comparative operators give rise to. The properties listed provide a road map for how to determine which operator a given comparative construction uses. One should first determine whether the construction is contextual or compositional. Supposing 
Phrasal Comparatives

\begin{tabular}{|c|c|c|c|c|c|c|c|}
\hline & $\begin{array}{l}\text { Variation } \\
\text { in Accept. }\end{array}$ & \begin{tabular}{c|c} 
Variation \\
in Interpret.
\end{tabular} & $\begin{array}{l}\text { Filled } \\
\text { Degree Slot }\end{array}$ & $\begin{array}{l}\text { Island } \\
\text { Sensitivity }\end{array}$ & $\begin{array}{l}\text { Range: } \\
\text { predicative, attributive, } \\
\text { adverbial, clausal }\end{array}$ & $\begin{array}{l}\text { Scope: } \\
\text { Bhatt \& Takahashi }\end{array}$ & $\begin{array}{l}\text { Scope: } \\
\text { Minimal Requirement Readings }\end{array}$ \\
\hline [[ - $\left.\left.e r_{\text {(degree) }}\right]\right]$ & Yes. & Yes. & Yes. & No. & $\begin{array}{c}\text { Seemingly } \\
\text { whole range. }\end{array}$ & $\begin{array}{l}\text { Seemingly like } \\
\text { Hindi and English. }\end{array}$ & Possibly Ambiguous." \\
\hline [I $\left.\left.-e r_{\text {(clausal) }}\right]\right]$ & No. & No. & No. & Yes. & Whole range. & Like English. & Ambiguous. \\
\hline$\left[\left[-e r_{\text {(Kennedy) }}\right]\right]$ & No. & No. & No. & Yes. & Predicative only. & $n / a$ & Narrow. \\
\hline [[ $\left.\left.-e r_{\text {(Heim) }}\right]\right]$ & No. & No. & No. & Yes. & $\begin{array}{c}\text { Predicative, attributive, } \\
\text { adverbial only. }\end{array}$ & Like Hindi. & Ambiguous. \\
\hline \multicolumn{8}{|c|}{$\begin{array}{l}\text { ") Scope interaction with the modal need depends on further factors for the contextual comparative, including the availability of degree abstraction } \\
\text { as governed by the Degree Abstraction Parameter (DAP). See Beck et al. } 2004 \text { and Beck et al. } 2009 \text { for discussion. }\end{array}$} \\
\hline
\end{tabular}

Figure 1 Crosslinguistic properties of comparative operators.

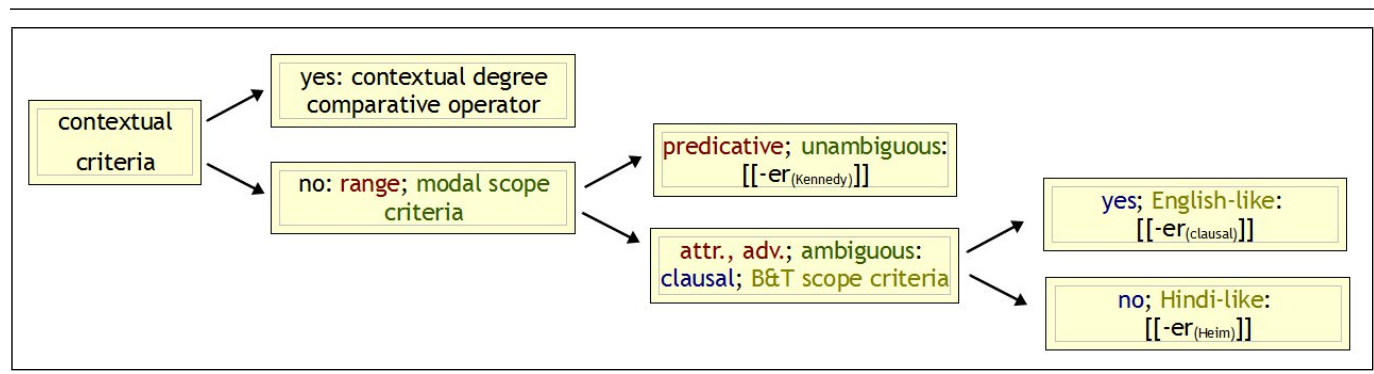

Figure 2 Roadmap to comparative operators.

that it is compositional, one can determine whether attributive, adverbial and clausal comparatives are available, and whether there is a scope ambiguity with modal verbs. Existence of attributive and adverbial comparatives and scope ambiguity with

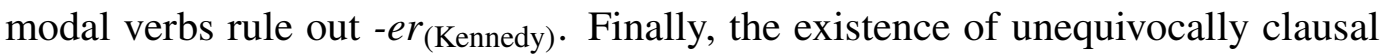
comparatives and English-like readings in Bhatt \& Takahashi-configurations speaks in favor of -er (clausal). The lack of clausal comparatives and Hindi-like readings in Bhatt \& Takahashi-configurations speaks in favor of $-e r_{(\text {Heim })}$. When we consider a particular comparative construction from an as yet semantically unanalyzed language, we can thus go through the decision tree provided in Figure 2.

Given one particular comparative constructions, the above criteria should thus allow us to determine which comparative operator occurs in this construction. What kinds of scenarios could we expect for comparatives crosslinguistically on this basis? Firstly, a language could have exactly one comparative. In that case, a simple run through the decision tree would hopefully give a clear answer to the question of which comparative operator is used in this language. Secondly, a language might have more than one comparative construction at its disposal, and the different constructions might use different comparative operators-which ones, to 
be determined individually by the criteria outlined. Thirdly, a language could have several comparative operators which, along with the comparative constructions they occur in, are indistinguishable by surface form. Such an ambiguous comparative operator could develop in stages. Which properties of comparative constructions are observable in this case depends on the combination of operator meanings (see below). We will see evidence for all three scenarios in the following sections.

\section{Evidence from First Language Acquisition}

On the grounds of the criteria presented in the last section, English falls into the class

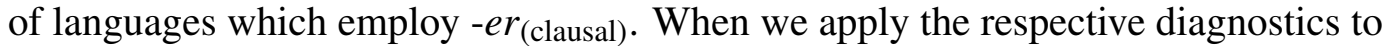
German, it turns out that German behaves just like English and it thus looks as if both

English and German only make use of $-e$ (clausal) $^{3}{ }^{3}$ Recall however, that $-e r_{\text {(Kennedy) }}$ accounts for a proper subset of the data that $-e r_{\text {(clausal) }}$ accounts for. This means that there might be a possibility that a language which uses -er (clausal) might also employ $-e r_{(\text {Kennedy) }}$, but our diagnostics are not sensitive to this distinction. In Tiemann et al. 2012, we report a corpus study on the acquisition of comparatives of three children acquiring American English and three children acquiring German. As it turns out, English learning children acquire comparatives with a than-constituent significantly earlier than German children. This leads us to suggest that English makes use of $-e r_{\text {(degree) }},-e r_{\text {(Kennedy) }}$, and $-e r_{\text {(clausal) }}$, whereas German only has $-e r_{\text {(degree) }}$ and -er (clausal) at its disposal. While the main focus in Tiemann et al. 2012 lies on the acquisition of a variety of different degree constructions and how they line up with the parametric approach presented in Beck et al. 2009, the present paper is mainly concerned with the acquisition of unmarked adjectives and comparatives (with and without than-constituents).

\subsection{Methodology}

We selected transcripts of spontaneous speech from CHILDES (MacWhinney 2000). For English, we looked at Adam and Sarah from Brown's (1973) corpus, and Ross from Brian MacWhinney's corpus. The German children selected were Cosima, Pauline, and Sebastian (collected by Rosemarie Rigol). We used the programs provided by CLAN to identify potentially relevant child utterances. The obtained results were analyzed for very first recorded use and age of acquisition, as well as for types of errors and their frequency. Following Stromswold 1996 and Snyder 2007, the age at which a child produced her or his first clear example of a construction followed soon after by regular use with a variety of lexical items was considered to be the age of acquisition for this construction (First of Repeated Uses, FRU).

3 See the appendix for the relevant data. 
Phrasal Comparatives

\begin{tabular}{c|c|c|c|c|c|c|}
\hline First Use & \multicolumn{3}{|c}{ English } & \multicolumn{4}{c}{ German } \\
& Adam & Sarah & Ross & Cosima & Pauline & Sebastian \\
Unmarked form & $2 ; 3$ & $2 ; 3$ & $1 ; 4$ & $1 ; 2$ & $1 ; 4$ & $2 ; 0$ \\
Comparative adj. & $2 ; 6$ & $2 ; 10$ & $2 ; 6$ & $2 ; 7$ & $1 ; 1$ & $3 ; 11$ \\
Than-phrases & $3 ; 5$ & $3 ; 11$ & $3 ; 5$ & $6 ; 6$ & $5 ; 9$ & $4 ; 8$
\end{tabular}

Table 1 Age of first recorded use.

\begin{tabular}{c|c|c|c|c|c|c|}
\hline FRU & \multicolumn{4}{|c}{ English } & \multicolumn{4}{c}{ German } \\
& Adam & Sarah & Ross & Cosima & Pauline & Sebastian \\
Unmarked form & $2 ; 3$ & $2 ; 3$ & $2 ; 6$ & $2 ; 0$ & $2 ; 5$ & $2 ; 0$ \\
Comparative adj. & $3 ; 4$ & $3 ; 7$ & $2 ; 6$ & $2 ; 9$ & $2 ; 8$ & $3 ; 11$ \\
Than-phrases & $4 ; 2$ & -4 & $3 ; 5$ & - & $6 ; 3$ & $4 ; 8$
\end{tabular}

Table 2 Age of acquisition.

\subsection{Results}

The results for the acquisition of the unmarked form of the adjective and of the comparative by German and American children are summarized above. Table 1 presents the results for the age of first recorded use. Table 2 specifies the age of acquisition. Below are some representative utterances from the corpora.

(42) Unmarked Adjectival Form:

CHI: my little kitty . (Sarah, age: 2;3.07, file: sarah002.cha)

(43) Comparative Adjective:

CHI: it will be cleaner . (Ross, age: 2;6.17, file: 20a1.cha)

(44) Than-Phrases:

a. CHI: go faster than a bullet . (Adam, age: 4;2.17, file: adam44.cha)

b. CHI: du bist naemlich kleiner als ich . you are namely smaller than I

(Pauline, age: 6;6.30, file: pa060630.cha)

To sum up, all children first acquire the unmarked form of the adjective, followed by comparatives without a than-constituent, followed by comparatives with a thanphrase. English speaking children, however, take the last step significantly earlier German speaking children do.

4 The low number of occurrences prevented us from determining the age of acquisition. 
Beck, Hohaus, Tiemann

\subsection{Discussion}

On the basis of these results, we propose four stages in the acquisition of comparatives. We suggest that the child begins with the adult semantics of an unmarked gradable adjective at stage 0 , though without arriving at this meaning as a combination of the Positive operator and a relational adjective meaning. We suggest she uses the lexical entry in (45) as a simple, uncomposed meaning. Once the child has acquired the comparative form of the adjective together with its correct meaning, we suppose that she uses the semantics in (46). In a next step, the child realizes that the meaning of (45) is derived by composing (47a) and (47b), resulting in (47c).

Stage 0: $\llbracket t a l l \rrbracket=\lambda x_{\langle e\rangle} \cdot x$ counts as tall in $c$

Stage 1: $\llbracket$ taller $\rrbracket=\lambda x_{\langle e\rangle}$. HEIGHT $(x)>d_{c}$

Stage 2a:

a. $\llbracket$ tall $\rrbracket=\lambda d_{\langle d\rangle} \cdot \lambda x_{\langle e\rangle} \cdot \operatorname{HEIGHT}(x) \geq d$

b. $\llbracket-e r_{\text {(degree) })} \rrbracket=\lambda \operatorname{Adj}_{\langle d,\langle e, t\rangle\rangle} \cdot \lambda d^{\prime}\langle d\rangle \cdot \lambda x_{\langle e\rangle} \cdot \operatorname{MAX}(\lambda d \cdot \operatorname{Adj}(d)(x))>d^{\prime}$

c. $\llbracket$ taller $d_{c} \rrbracket=\llbracket$-er $($ degree $) \rrbracket(\llbracket$ tall $\rrbracket)\left(\llbracket d_{c} \rrbracket\right)=\lambda x$. HEIGHT $(x)>d_{c}$

At this stage, English learning children also master than-phrases with predicative adjectives. This finding is quite astonishing since linguistic analysis has not, to our knowledge, proposed that there is any substantial difference between English and German comparatives. The findings for German are what we expect given the analyses in Lechner 2004 and Bhatt \& Takahashi 2011 Those works argue that than-constituents in English as well as German are uniformly reduced from a clausal source. Hence apparent than-phrases are really underlyingly clausal, and all such structures should be acquired at the same time. This is what happens in German, but not in English. The acquisitional finding suggests that a simpler analysis is available for English than-phrases which is unavailable in German; cf. Tiemann 2009. We therefore propose that there exists a stage $2 b$, as in (48), at which only English children acquire a simpler meaning for the phrasal comparative morpheme, $-e r_{\text {(Kennedy) }}$. We suggest that in a final step, English as well as German children acquire comparatives with a than-constituent that is derived from a clausal source. Hence, this is the stage at which German children acquire comparatives with than-constituents. At this point, the semantic knowledge is as in (49).

Stage 2b:

$$
\begin{aligned}
& \llbracket-\operatorname{er}_{(\text {Kennedy })} \rrbracket=\lambda \operatorname{Adj}_{\langle d,\langle e, t\rangle\rangle} \cdot \lambda y_{\langle e\rangle} \cdot \lambda x_{\langle e\rangle} \cdot \\
& \operatorname{MAX}(\lambda d \cdot \operatorname{Adj}(d)(x))>\operatorname{MAX}\left(\lambda d^{\prime} \cdot \operatorname{Adj}\left(d^{\prime}\right)(y)\right)
\end{aligned}
$$

Stage 3: $\llbracket-e r_{\text {(clausal) })} \rrbracket=\lambda d_{\langle d\rangle} \cdot \lambda D_{\langle d, t\rangle} \cdot \operatorname{MAX}(D)>d$ 


\begin{tabular}{c|c|c|c|}
\hline First Use & \multicolumn{3}{|c}{ English } \\
& Adam & Sarah & Ross \\
Comparative adjectives & $2 ; 6$ & $2 ; 10$ & $2 ; 6$ \\
Predicative comparatives with than & $3 ; 5$ & $3 ; 11$ & $3 ; 5$ \\
Attributive comparatives with than & $3 ; 5$ & $3 ; 11$ & $3 ; 5$ \\
Adverbial comparatives with than & $4 ; 2$ & & $4 ; 2$
\end{tabular}

Table 3 First use of attributive and adverbial comparatives with than.

\begin{tabular}{|c|c|c|c|}
\hline \multirow[t]{2}{*}{ FRU } & \multicolumn{3}{|c|}{ English } \\
\hline & Adam & Sarah & Ross \\
\hline Comparative adjectives & $3 ; 4$ & $3 ; 7$ & $2 ; 6$ \\
\hline Predicative comparatives with than & $4 ; 2$ & - & $3 ; 5$ \\
\hline Attributive comparatives with than & - & - & $4 ; 4$ \\
\hline Adverbial comparatives with than & $4 ; 2$ & & $5 ; 6$ \\
\hline
\end{tabular}

Table 4 Acquisition of attributive and adverbial comparatives with than.

As discussed in section 2, - $e r_{\text {(Kennedy) }}$ cannot undergo QR and is thus only suitable for predicative uses of the comparative. Hence, in order to test whether our assumptions about stage $2 \mathrm{~b}$ are correct, we checked at which age English children acquired attributive and adverbial uses of the comparative. Our prediction is that these comparatives are acquired significantly later than predicative comparatives because they require a comparative operator which is mobile at LF. This operator, however, is not acquired before stage 3. The data from Ross in Tables 3 and 4 above is suggestive of such a sequencing: Ross acquires comparatives without a than-constituent earlier than any type of comparative with an overt than-constituent. Acquisition of predicative comparatives with than-phrases is earlier than acquisition of adverbial comparatives with than-constituents, as is the acquisition of attributive comparatives with than-constituents when compared to adverbial comparatives with than-constituents. All these differences are significant $(p<.05)$ by a Binominal Test.

To conclude, the age difference between English and German speaking children in the acquisition of than-phrases led us to suggest that English but not German makes use of $-e r_{\text {(Kennedy) }}$. This hypothesis receives additional support from the fact that English children acquire predicative comparatives with than-constituents significantly earlier than attributive and adverbial comparatives with than-constituents, as expected since $-e r_{\text {(Kennedy) }}$ is only suitable for predicative uses of the comparative. Figure 3 on the next page summarizes the individual stages in the acquisition of 


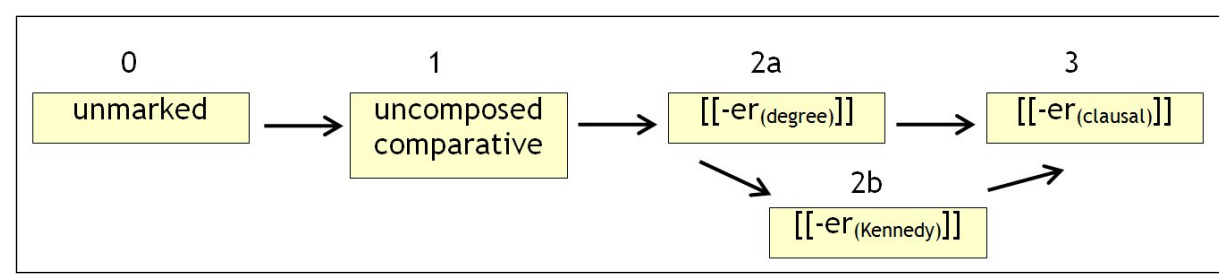

Figure 3 Stages in the acquisition of comparatives in English and German.

comparatives. Whilst English children go from stage 2a through stage $2 \mathrm{~b}$ to stage 3, German children go directly from stage 2 a to stage 3 .

Even though English and German comparatives with than-constituents look superficially the same on the surface, they are not. Our results reveal that there are subtle differences between these two languages. This, in turn, raises the question of how exactly other languages express comparatives. We will look at the crosslinguistic data in more detail in the next section.

\section{The Crosslinguistic Picture}

Languages may employ several of the comparative operators introduced in section 2 , and these may or may not have the same surface form. Which combinations, then, do we find in languages other than German and English? We speculate that language development might follow language acquisition and that degree comparatives are basic. This would mean that if a language has comparatives at all, it should have degree comparatives.

This section will follow the roadmap laid out in section 1 in that we will first present languages which employ a contextual strategy to determine the standard of comparison (subsection 4.1). We will then discuss the various compositional strategies for comparatives (subsection 4.2). We will see that some languages will feature in all four categories, while others will only show up in one. All data that this section makes reference to is provided in the appendix.

\subsection{Contextual Degree Comparatives}

Whereas English and German have -er(degree) as one of several operators in their inventory, Japanese is an example of a language that employs only the contextual strategy. Apart from the properties listed in the table in Figure 4 and discussed in section 2, additional evidence for a contextual analysis of Japanese comparatives 
Phrasal Comparatives

\begin{tabular}{|l|c|c|c|c|}
\hline & Variation in Acceptability & Variation in Interpretation & Island Sensitivity & Filled Degree Slot \\
\hline Japanese $[$ yori $]$ - & Yes. & Yes. & -not elicited- & Yes. \\
\hline English $[$ compared to $]$ & Yes. & Yes & No. & Yes. \\
\hline German $[$ im Vergleich $z u]$ & Yes. & Yes. & No. & Yes. \\
\hline
\end{tabular}

Figure 4 Contextual degree comparatives.

comes from the use of yori-constituents outside of comparatives and from the availability of multiple yori-constituents. (For further discussion of Japanese, the reader is also directed to Beck et al. 2004 and Beck et al. 2009: 10-13.)

It would be nice to find another language that relies on a contextual strategy only. Sāmoan is a promising candidate for such a language, contra Hohaus (2012). We do find the relevant variation in interpretation and do not seem to find island sensitivity. Remember that a compositional analysis of a relevant example such as (50) would require movement of the comparative operator out of the relative clause island in order to syntactically derive the required degree relation in (51).

(50) Sa fa'atau e Malia fa'amalu e tele i lō Falani. TAP buy ERG. Mary umbrella TAP be.many PREP. STD Frank

'Compared to Frank, Mary bought umbrellas which are more numerous.' (Villalta 2007: 6)

$$
\lambda d_{\langle d\rangle} \cdot \lambda x_{\langle e\rangle} \cdot \exists y[\operatorname{umbrella}(y) \& \operatorname{buy}(y) \text { (Mary) \& } \operatorname{CARD}(y) \geq d]
$$

Corresponding English (and German) examples therefore yield non-sensical interpretations once we employ a than-clause (or an als-clause) rather than compared to (or im Vergleich zu).

\subsection{Compositionally Integrated Standards}

When it comes to compositional paths to comparatives, we find some uncharted territory in that our (admittedly small) sample does not include a language that employs only -er (Kennedy), while single-operator strategies are attested for -er $r_{\text {(Heim) }}$ and $-e r_{\text {(clausal). }}$. Greek on the other hand seems to be picking from the spoil of riches and is special in that it makes use of the entire inventory of degree operators available. Quite contrary to English, it is maximally transparent as the three different compositional comparatives introduce their standard in a different fashion. Let us take a closer look at the results, which are summarized in the table in Figure 5 at the top of the next page. 
Beck, Hohaus, Tiemann

\begin{tabular}{|c|c|c|c|c|c|c|c|}
\hline & \begin{tabular}{|c|} 
Predicative \\
Comparative
\end{tabular} & $\begin{array}{c}\text { Attributive } \\
\text { Comparative }\end{array}$ & $\begin{array}{c}\text { Adverbial } \\
\text { Comparative }\end{array}$ & $\begin{array}{l}\text { Clausal } \\
\text { Standards }\end{array}$ & $\begin{array}{c}\text { Scope: } \\
\text { Bhatt \& Takahashi (2011) }\end{array}$ & $\begin{array}{c}\text { Scope: } \\
\text { Minimal Requirement Readings }\end{array}$ & Conclusion \\
\hline Greek [GEN.] & Yes. & [In situ.] & No. & No. & -not elicited- & -not elicited- ${ }^{*}$ & [[ $\left.\left.-e r_{\text {(Kennedy) }}\right]\right]$ \\
\hline English [than] & Yes. & [In situ.] & No. & No. & (No.) & (No.) & [[ - $\left.\left.-r_{\text {(Kennedy) }}\right]\right]$ \\
\hline Greek [apo] & Yes. & Yes. & Yes. & No. & -not elicited- & -not elicited-") & [[ -er (Heim) ]] \\
\hline Hindi & Yes. & Yes. & Yes. & No. & Wide. & Yes. & [[ $\left.\left.-e r_{\text {(Heim) }}\right]\right]$ \\
\hline Turkish & Yes. & Yes. & Yes. & No. & -not elicited- & Yes. & [[ $\left.\left.-e r_{\text {(Heim) }}\right]\right]$ \\
\hline German $[a l s]$ & Yes. & Yes. & Yes. & Yes. & Narrow. & Yes. & [I $\left.\left.-e r_{\text {(clausal) }}\right]\right]$ \\
\hline English [than] & Yes. & Yes. & Yes. & Yes. & Narrow. & Yes. & [I $\left.\left.-e r_{\text {(clausal) }}\right]\right]$ \\
\hline Greek [apo'ti] & Yes. & Yes. & Yes. & Yes. & -not elicited- & -not elicited-") & [I $\left.\left.-e r_{\text {(clausal) }}\right]\right]$ \\
\hline
\end{tabular}

Figure 5 Degree comparatives with compositionally integrated standards.

Immobile Comparative Operators So far, we have no example of a language that employs - $e r_{\text {(Kennedy) }}$ as its only operator under a compositional strategy. Such a language would only allow for predicative comparatives and would not exhibit scopal ambiguities. A candidate for such a language is Yorùbá, which lacks attributive comparatives. Further empirical investigation will show whether Yorùbá grammar indeed employs the comparative operator of type $\langle\langle d,\langle e, t\rangle\rangle,\langle e,\langle e, t\rangle\rangle\rangle$. Given their properties listed above, Greek Genitive-marked comparatives seem to employ -er (Kennedy). ${ }^{5}$ The in situ interpretation of Greek Genitive-marked comparatives when used attributively, as in (52), deserves some explanation: This type of attributive comparative receives a local interpretation, under which Anna's height is directly compared to the height of her husband. (Yet, we do not derive a contradiction regarding her being male.) This interpretation of the comparative in (52) is derived as sketched in (53).

I Anna pandreftike enan psilotero tis andra. the Anna married(3sg.) a tall -er (Kennedy) her(GEN.) man

'Anna ${ }_{i}$ married a man taller than her ${ }_{i}$.'

(Merchant 2011: 3)

[ [a [AP [tall -er(Kennedy) $]$ than Anna] man ] [1 [Anna married $\left.\left.\left.t_{1,\langle e\rangle}\right]\right]\right]$ interpretation of the Adjectival Phrase:

$\lambda x_{\langle e\rangle} \cdot \operatorname{MAX}(\lambda d \cdot \operatorname{HEIGHT}(x) \geq d)>\operatorname{MAX}\left(\lambda d^{\prime} . \operatorname{HEIGHT}(\right.$ Anna $\left.) \geq d^{\prime}\right)$

truth conditions:

$\exists z[\operatorname{man}(z) \& \operatorname{HEIGHT}(z)>\operatorname{HEIGHT}($ Anna $) \& \operatorname{marry}(z)($ Anna $)]$

5 Merchant (2011) however pursues an analysis of the Genitive-marked comparative in Greek that employs $-e r_{(\text {Heim })}$, to which he adds a stipulation against Quantifier Raising of the operator in the case of attributive comparatives. Under the analysis presented here, the Greek data would fall out naturally. 
Phrasal Comparatives

A side remark regarding English: Remember that - $e r_{\text {(Kennedy) }}$ accounts for a proper

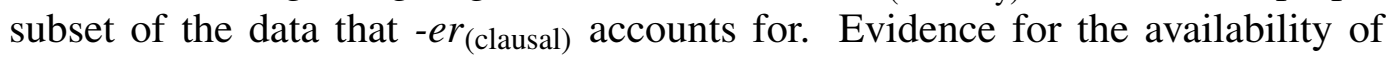
- $e r_{\text {(Kennedy) }}$ in English comes solely from the time course of first language acquisition presented in the previous section.

Versatile Phrasal Comparative Operators Judging from the properties in the table in Figue 5 above, Greek, Hindi and Turkish employ -er $r_{(\text {Heim })}$. Unlike Greek however, Hindi and Turkish do not have a clausal operator at their disposal. Note that we are not able to tell whether they additionally have $-e r_{\text {(Kennedy). }}$ (See the related comment above.)

Clausal Comparative Operators German employs only a clausal comparative operator, while in English and Greek this clausal operator is one of many in the inventory of compositional comparative operators available in the grammar. Greek differs from English, however, in that it marks the clausal standard of comparison differently from its phrasal standards of comparison.

\section{Concluding Remarks}

We have shown that the two lexical entries for phrasal comparative operators prominent in the semantic literature (i.e. $-e r_{(\text {Kennedy) }}$ and $-e r_{(\text {Heim })}$ ) give rise to a totally different behavior of the comparatives they are contained in. It is thus insufficient to recognize a comparative as a phrasal comparative. Further data are required to establish its semantics. Furthermore, before we can discuss whether a comparative with an apparently phrasal than-constituent should be analyzed as reduced clausal, or as genuinely phrasal with either phrasal comparative operator, we need to make sure that it is a compositional comparative at all. That is, a contextual analysis ought to be considered, and-where appropriate—rejected, first. We hope to have provided a first set of criteria for making such decisions with the empirical properties that distinguish the various operators. The small language sample we have discussed already illustrates that languages make use of a fairly wide range of options when it comes to their choice(s) of comparative operator(s).

\section{References}

Beck, Sigrid. 2011. Comparison constructions. In Claudia Maienborn, Klaus von Heusinger \& Paul Portner (eds.), Semantics: An international handbook of natural language meaning, vol. 2, 1341-1389. Berlin: De Gruyter.

Beck, Sigrid. 2012. Lucinda driving too fast again. The scalar properties of ambiguous than-clauses. Journal of Semantics (online first). 1-63. 
Beck, Hohaus, Tiemann

Beck, Sigrid, Svetlana Krasikova, Daniel Fleischer, Remus Gergel, Stefan Hofstetter, Christiane Savelsberg, John Vanderelst \& Elisabeth Villalta. 2009. Crosslinguistic variation in comparison constructions. Linguistic Variation Yearbook 9. $1-66$.

Beck, Sigrid, Toshiko Oda \& Koji Sugisaki. 2004. Parametric variation in the semantics of comparison: Japanese versus English. Journal of East Asian Linguistics 13. 289-344.

Beck, Sigrid \& Uli Sauerland. 2000. Cumulation is needed: A reply to Winter (2000). Natural Language Semantics 8. 349-371.

Bhatt, Rajesh \& Shoichi Takahashi. 2011. Reduced and unreduced phrasal comparatives. Natural Language and Linguistic Theory 29. 581-620.

Brown, Roger. 1973. A first language: The early stages. Cambridge: Harvard University Press.

Hayashishita, J.-R. 2009. Yori-comparatives: A reply to Beck et al. (2004). Journal of East Asian Linguistics 18. 65-100.

Heim, Irene. 1985. Notes on comparatives and related matters. Manuscript, University of Texas at Austin.

Heim, Irene. 2001. Degree operators and scope. In Caroline Féry \& Wolfgang Sternefeld (eds.), Audiatur vox sapientiae: A Festschrift for Arnim von Stechow, 214-239. Berlin: Akademie-Verlag.

Hohaus, Vera. 2012. Directed motion as comparison: Evidence from Samoan. In Elizabeth Bogal-Allbritten (ed.), Semantics of Underrepresented Languages of the Americas (SULA) 6, 335-348.

Kennedy, Christopher. 1997. Projecting the adjective: The syntax and semantics of gradability and comparison: University of California, Santa Cruz dissertation.

Kennedy, Christopher. 2007. Vagueness and grammar: The semantics of absolute and relative gradable adjectives. Linguistics and Philosophy 30. 1-45.

Lechner, Winfried. 2004. Ellipsis in comparatives. Berlin: De Gruyter.

MacWhinney, Brian. 2000. The CHILDES project: Tools for analyzing talk. Hillsdale: Lawrence Erlbaum 3rd edn.

Merchant, Jason. 2011. Genitives of comparison in Greek. Manuscript, University of Chicago.

Oda, Toshiko. 2008. Degree constructions in Japanese: University of Connecticut dissertation.

Pinkal, Manfred. 1989. Die Semantik von Satzkomparativen. Zeitschrift für Sprachwissenschaft 8. 206-256.

Shimoyama, Junko. 2012. Reassessing crosslinguistic variation in clausal comparatives. Natural Language Semantics 20(1). 83-113.

Snyder, William. 2007. Child language: The parametric approach. Oxford: Oxford University Press. 
Phrasal Comparatives

von Stechow, Arnim. 1984. Comparing semantic theories of comparison. Journal of Semantics 3(1-2). 1-77.

Stromswold, Karin J. 1996. Analyzing children's spontaneous speech. In Dana McDaniel, Cecile McKee \& Helen Smith Cairns (eds.), Methods for assessing children's syntax, 23-53. Cambridge: The MIT Press.

Tiemann, Sonja. 2009. The acquisition of comparison: A corpus based analysis. Eberhard Karls Universität Tübingen MA thesis.

Tiemann, Sonja, Vera Hohaus \& Sigrid Beck. 2012. Crosslinguistic variation in comparison: Evidence from child language acquisition. In Britta Stolterfoht \& Sam Featherston (eds.), Empirical approaches to linguistic theory: Studies of meaning and structure, 115-146. Berlin: De Gruyter.

Villalta, Elisabeth. 2007. Fragebogen zu Komparativen im Samoan. Handout, Eberhard Karls Universität Tübingen.

Sigrid Beck and Vera Hohaus

Eberhard Karls Universität Tübingen

Englisches Seminar

Wilhelmstraße 50

72074 Tübingen (Germany)

sigrid.beck@uni-tuebingen.de

vera.hohaus@uni-tuebingen.de

Sonja Tiemann

Eberhard Karls Universität Tübingen

Sonderforschungsbereich 833

Nauklerstraße 35

72074 Tübingen (Germany)

sonja.tiemann@uni-tuebingen.de 